\title{
Knowledge and Attitude about Prevention of Iodine Deficiency Disorders (IDD) among Women and Quantification of Iodide found in Table Salt in Central Highland of Ethiopia
}

\author{
Abebe Ferede*1, Muluemebet Abera $^{2}$ and Tefera Belachew ${ }^{2}$ \\ ${ }^{1}$ Arsi University, College of Health Science, Department of Public Health, Asella , Ethiopia \\ ${ }_{2}^{2}$ Jimma University, Faculty of Public Health, Department of Nutrition and Dietetics, Jimma, Ethiopia
}

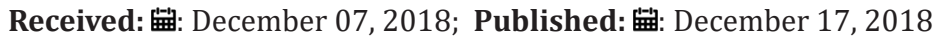

*Corresponding author: Abebe Ferede, College of Health Science, Department of Public Health, Asella, Arsi and Jimma Universities, Ethiopia

\begin{abstract}
Objective: Monitoring systems in broad part of each country is notable effort to eliminate iodine deficiency disorders (IDD). Although Ethiopian government developed micronutrient deficiency prevention and control guideline in 2005 and deployed health extension workers to give behaviour change communication for use of iodized salt. There is no published data of knowledge and attitude of mothers on iodized salt and the iodine content of table salt in Ethiopia. This study aimed to assess knowledge and attitude of women towards IDD prevention through quantifying of iodine in table salt at central highland of Ethiopia.
\end{abstract}

Methods: A community based cross-sectional study was carried out among 1012 women in the reproductive age group selected from central highland of Ethiopia. A multistage sampling method was implemented to select study area and households (HH). Study participants were interviewed using structured interviewer administered questionnaire. Table salt samples were collected from each woman and from headquarter markets. Table salt samples transported to Ethiopian Public Health institute (EPHI) for determination of their iodine content using titration method each sample iodine content measured in milligram of iodine per $\mathrm{kg}$ of salt equivalent to - parts per million(ppm)

Results: From 1012 women interviewed, 683(67.0\%) of women participated in the study lacked knowing IDD and 505 (49.9\%) know the use of iodised salt for the prevention of IDD. Poor knowledge was strongly associated with low level of education (Adjusted Odds Ratio [AOR $=4.61$, 95\% CI: 3.03, 7.023]. Analyses of table salt samples taken from HHs had 73 (60.83\%) of samples in allowable standard limit (15 to 40ppm), over standard limit (>40ppm) $46(38.33 \%)$ and blow standard limit (<15ppm) $1(0.83 \%)$. A total of $119(99.17 \%)$ HHs had met their requirement of iodine per person per day. The average mean and standard deviation (SD) were $45.29+14.47 \mathrm{mg} / \mathrm{kg}$ ( ppm).

Conclusion: Knowledge among women towards prevention of IDD was very poor. More than $90 \%$ iodised salt had provided adequate (150 $\mu \mathrm{g})$ of iodine per person per day. Therefore, this study strongly encourages behaviour change communication (BCC) to the community. Mid urine iodine concentration techniques among children is recommended for to actualized the pregress of iodized salt intervention.

Keywords: Iodide Quantity Iodised Salt; IDD Titration; Women's Knowledge; Ethiopia

Abbreviations: AOR: Adjusted Odds Ratio; CI: Confidence Interval, EPHI - Ethiopian Public Health Institute, ETB - Ethiopian Birr (currency); HH: Household; HHs: Households; IDD: Iodine Deficiency Disorders, PPM: Parts Per Million, KG: Kilogram, MG: Milligram, SD: Standard Deviation; $\mu$ g: Microgram, UNICEF: United Nations Children's Fund

\section{Introduction}

Iodine is an essential component of thyroid hormones which controls metabolic processes in the body. It plays a major role in mental development and physical growth [1]. Due to its mountainous topography, the highland of Ethiopia has been leaching out iodine from the soil aggravated by accelerated deforestation and soil erosion. Consequently, soil in such areas has low in iodine content [2]. Furthermore, foods demonstrated to have goitorogenic effect are used as staples in the highland areas 
[3]. Plants grown in iodine-deficient area can never provide enough iodine to the consumer people. Likewise, livestock living the same place do not meet their requirements of iodine being at risk for iodine deficiency related disorders [4]. IDD can lead to impaired mental development, adverse effects on growth, infant mortality, hypothyroidism, reproductive failure, and endemic goitre [5]. Changing dietary habits or eating specific kinds of foods cannot prevent IDD; however, it corrects by supplying iodine from external sources. Reminiscent of salt iodisation ensures a minimum of $150 \mu \mathrm{g}$ iodine/day requirement of individual [6].

Salt has to be chosen as a vehicle based on a capacity to iodize it and economic context of population which help to access it without any barrier [4]. Iodised salt is the easiest and least expensive to prevent and control of IDD as compared to other nutrient disorders [5]. It was prepared so that people daily consume all iodine that is needed for the prevention and control of IDD [7]. The minimum requirement of iodine to prevent goitre is estimated to be between 50 and $75 \mu \mathrm{g}$ (microgram/day or $\sim 1 \mu \mathrm{g} / \mathrm{kg}$ of body weight [8]. However, adult daily requirement ranges from 100 to $200 \mu \mathrm{g}$ and the average is $150 \mu \mathrm{g}$ [8]. World Health Organisation (WHO) recommends that at least $90 \%$ of households use adequately iodised salt which contains 15parts per million (ppm) or more at the household level [9]. Ethiopian government endorsed the guideline for prevention and control of micronutrient deficiencies, deployed rural and urban health extension workers to educate the public about importance of iodized salt consumption and started iodizing salt from Afdera Lake in Afar region. However, there is no study that assessed both knowledge and attitude about iodized salt and the iodine content of iodized salt [10].

Women are the most vulnerable segments of the population to IDD in severely iodine deficient areas and they should be targeted for sustainable elimination of IDD [7]. Therefore, this assessed the knowledge and attitude of women who are responsible for purchasing and using table salt in food processing as well as determined the iodine content of salt. Programmatic monitoring of iodide salt intervention at the household level is essential to prevent public health risk from iodine deficiency [9]. Assessing women's knowledge and attitude towards prevention and control of IDD in the community where illiteracy and communication barriers are common is critical input for tailoring intervention strategies.

\section{Methods and Materials}

\section{Study Area}

This study was conducted in Central highland of Ethiopia which includes area with altitude ranging from 2100 to 3000 found near to Arsi Bale plateau and the neighbouring of Chilalo Mountain districts. These districts included in the study were Munesa, Asella, Limuna Bilalo, Digeluna Tijo, Honkolo Wabe. Historical rainfall and temperature of the study area from 1967 to 2008 interval mean of annual rainfall was $2200 \mathrm{~mm}$ to $2350 \mathrm{~mm}$ and the interval mean daily maximum temperature was also ranging from $21.5^{\circ} \mathrm{C}$ to $23^{\circ} \mathrm{C}$ and minimum interval mean from $10.0^{\circ} \mathrm{C}$ to $9.0^{\circ} \mathrm{C}$ [11].

\section{Study Design}

Community based cross sectional study was conducted from January to June 2018. Sampling method: Multi-stage sampling method was applied to select highland areas with considerable (above $2400 \mathrm{~m}$ ) altitude and had history of mean annual rainfall via $2200 \mathrm{~mm}$ to $2350 \mathrm{~mm}$ of found central part of Ethiopia includes Arsi and Bale provinces mountains and stratified into nearest districts to the mountains [11]. Followed to these, simple random sampling method was used to select eight districts from all districts located near to the mountains. This more stratified into kebeles (small level of administrations) and 2 kebeles were selected randomly from each selected district and town.

\section{Study Population Sampling}

Systematic sampling was used to select households and 1012 women from selected kebeles. Selected women were interviewed using structured interviewer administered questionnaire to assess their knowledge and attitude toward IDD, IDD prevention and iodised salt utilization. Table salt sampling: All 1012 selected women for the study provided table salt samples which represent each $\mathrm{HH}$ table salt. In the first stage sampling 1012 samples were collected and consequently, 120 samples were picked with systematic randomly sampling for lab analysis. In addition to these, 24 samples were randomly selected from 8 distract headquarter markets; from each district 3 samples from 3 different directions of each market. Table salt samples were prepared and each weighted of $10 \mathrm{gm}$ [4]. The number of table salt samples was limited to 144 due to titration test procedure is a time-consuming [9]. The samples were transported to Ethiopian public health institute (EPHI) food and nutrition laboratory and analysed.

\section{Laboratory Measurement of Iodine in Salt}

All salt samples tested using standard titration method in EPHI food and nutrition laboratory. Analysis procedure used all required principles and recommendations of the British Pharmacopeia and International Council for Control of Iodine Deficiency Disorders (ICCIDD) to determine the quality of iodine in salt [3]. The procedure started with weighting of $10 \mathrm{gm}$ salt for each sample and adding into conical flak; then added $50 \mathrm{ml}$ boiled distilled water \& shaked to dissolve completely. Subsequently, pipette out $1 \mathrm{ml}$ of $2 \mathrm{~N}$ sulphuric acid $\& 5 \mathrm{ml}$ of $10 \%$ potassium iodide were added the solution. The solution turns yellow then the flask closed with stopper \& put it in the dark place for 10 minute in closed box. Poured $0.005 \mathrm{~N}$ sodium thiosulphate into the burette and adjust the level to zero.

After 10 minutes take the flask out of the dark and titrated with normal solutions $0.005 \mathrm{M}$ of sodium thiosulfate and stop titration when the solution turns to light yellow. Then, $1 \mathrm{ml}$ of $1 \%$ Starch solution was added and the solution turned to deep purple. Next, titration continued until the purple colour disappeared and the solution becomes colourless. Then the burette reading record and the iodine content of the sample in parts per million interpreted from the attached table. In this study, 120 table salts samples from the $\mathrm{HH}$ and 24 from headquarter markets were tested for iodine 
content. The most frequent samples were classified into three groups based on their iodine content $(\mathrm{ppm}=\mathrm{mg}$ iodine per $\mathrm{kg}$ of salt): under standard limit (<15ppm) level; allowable standard limit from 15-40ppm; and over standard limit (>40ppm) [3].

\section{Data were Entered and Analysed}

By using the Statistical Package for Social Science statistical software for windows, version 21. Descriptive statistical methods were used for presenting women's' knowledge and attitude towards IDD data by using proportions and frequencies. Logistic regression models were used to identify predictors of poor knowledge and attitude towards IDD among women. Odds ratios with $95 \%$ of confidence intervals (CIs) were computed to assess the presence and degree of association with the outcome variables.
P-value less than 0.05 was used to declare a statistically significant association. Table salt analysis data were determined using mean, SD and frequency of table salt iodide content in salt. One-Sample $\mathrm{T}$ Test used to determine if there were any significant differences in iodine values in salt samples versus to standard iodine values and comparing average iodine values in salt samples (ppm). The significance level was considered at $\mathrm{P}<0.05$.

\section{Results}

From 16 Kebeles,1012 women were included in the study, major of $776(76.7 \%)$ study subjects were in the age 20 to 35years and their main age was 29+8year; above one-thirds of 392(38.7\%) had high school education and 174(17.2\%) were can not read and write (Table 1).

Table 1: Socio demographic status of study subjects in Central Highland of Ethiopia, 2018.

\begin{tabular}{|c|c|c|}
\hline Variables & Frequency $(n=1012)$ & Percent(\%) \\
\hline \multicolumn{3}{|c|}{ Maternal Age } \\
\hline Age $<20$ & 88 & 8.7 \\
\hline Age 2035 & 776 & 76.7 \\
\hline Age $>35$ & 148 & 14.6 \\
\hline \multicolumn{3}{|c|}{ Education Levels } \\
\hline Illiterate & 171 & 16.9 \\
\hline Grade $1-4$ & 141 & 13.9 \\
\hline Grade 5-8 & 307 & 30.3 \\
\hline Grade $9-12$ & 393 & 38.8 \\
\hline \multicolumn{3}{|c|}{ Marital Status } \\
\hline Single & 29 & 2.9 \\
\hline Married & 919 & 90.8 \\
\hline Divorced & 43 & 4.2 \\
\hline Widowed & 15 & 1.5 \\
\hline Separated & 6 & .6 \\
\hline \multicolumn{3}{|c|}{ Occupation } \\
\hline House wife & 465 & 45.9 \\
\hline Farmer & 170 & 16.8 \\
\hline Business women & 157 & 15.5 \\
\hline Gov.employee & 99 & 9.8 \\
\hline Daily labourer & 68 & 6.7 \\
\hline NGO employee & 14 & 1.4 \\
\hline Student & 11 & 1.1 \\
\hline House servant & 13 & 1.3 \\
\hline None & 15 & 1.5 \\
\hline \multicolumn{3}{|c|}{ Family size } \\
\hline$<5$ members & 823 & 81.3 \\
\hline 5-8 members & 67 & 6.6 \\
\hline
\end{tabular}




\begin{tabular}{|c|c|c|}
\hline \multicolumn{3}{|c|}{ Annul Income (Birr) } \\
\hline and more members & 447 & 42.1 \\
\hline$<1000$ & 484 & 47.2 \\
\hline $1000-5,000$ & 78 & 7.8 \\
\hline $5001-10,000$ & 3 & 3.0 \\
\hline$>10,000$ & & \\
\hline
\end{tabular}

Note: Birr-Ethiopian currency, n- study sample size.

\section{Study Subjects' Knowledge}

In this study, most women 637 (63.0\%) accessed to iodised salt utilization communication through different means and 354(35\%) study subjects were accessed information via radio. Majority $683(67.0 \%)$ of women participated in the study lacked awareness (knowing) towards IDD. Below the average 453 (44.8\%) of women participated in the study had recognized the prevention method of iodine deficiency disorders (IDD). Among study subjects, 560 (55.3\%) them didn't recognize about IDD and 507(50.1\%) didn't know the use of iodised salt in food process (Table 2).

Table 2: Knowledge and attitude status of study subjects towards IDD, IDD prevention and iodised sat utilization in Central Highland of Ethiopia, 2018.

\begin{tabular}{|c|c|c|c|}
\hline Variables & Categories & Frequency $(n=1012)$ & Percentage (\%) \\
\hline \multicolumn{4}{|c|}{ Iodised salt utilization communication accessed } \\
\hline & & 375 & 37 \\
\hline & & 637 & 63 \\
\hline \multicolumn{4}{|c|}{ Sources of communication } \\
\hline & & 354 & 35 \\
\hline & & 133 & 13.1 \\
\hline & & 173 & 17.1 \\
\hline & & 352 & 34.8 \\
\hline \multicolumn{4}{|c|}{ Awareness (knowing) of IDD } \\
\hline & & 683 & 67.49 \\
\hline & & 329 & 32.61 \\
\hline \multicolumn{4}{|c|}{ Recognition to Iodine deficiency disorders } \\
\hline & & 560 & 55.3 \\
\hline & & 452 & 44.7 \\
\hline \multicolumn{4}{|c|}{ Understand the cause of IDD } \\
\hline & & 237 & 23.4 \\
\hline & & 775 & 76.6 \\
\hline \multicolumn{4}{|c|}{ Know goitre as a course of iodine deficiency } \\
\hline & & 572 & 56.5 \\
\hline & & 440 & 43.5 \\
\hline \multicolumn{4}{|c|}{ Know prevention method of IDD } \\
\hline & & 559 & 55.2 \\
\hline & & 453 & 44.8 \\
\hline \multicolumn{4}{|c|}{ Conclusive communication on intake of iodine } \\
\hline & & 528 & 52.2 \\
\hline & & 484 & 47.8 \\
\hline \multicolumn{4}{|c|}{ know the use of iodised salt in food process } \\
\hline & & 507 & 50.1 \\
\hline
\end{tabular}




\begin{tabular}{|c|c|c|}
\hline Yes, know & 505 & 49.9 \\
\hline \multicolumn{3}{|c|}{ Usual time for adding iodised salt during food cooking } \\
\hline Early cooking time & 576 & 56.9 \\
\hline Mid cooking time & 210 & 20.8 \\
\hline End of cooking & 226 & 22.3 \\
\hline \multicolumn{3}{|c|}{ Remark taken during purchasing iodised salt } \\
\hline No & 981 & 96.9 \\
\hline Yes & 31 & 3.1 \\
\hline \multicolumn{3}{|l|}{ Handling of table salt } \\
\hline With cover & 439 & 43.4 \\
\hline Without cover & 573 & 56.6 \\
\hline \multicolumn{3}{|c|}{ Table salt had specific storage place } \\
\hline No & 487 & 48.1 \\
\hline Yes & 525 & 51.9 \\
\hline \multicolumn{3}{|c|}{ Consume cabbage, broccoli and other vegetables as staple food } \\
\hline Yes & 618 & 61.1 \\
\hline No & 394 & 38.9 \\
\hline
\end{tabular}

Note: IDD- Iodine deficiency disorders, n-study sample size.

\section{Study Subjects' Attitude}

Women who had attitude to add iodised salt at appropriate time of cooking food were only 226 (22.3\%) which mean with the intention of majority of the study participants did not feel about iodized salt utilization. Women those focus to handled iodised salt with cover were 439(43.4\%). Consuming cabbage, broccoli and vegetables as staple food among study subject was $618(61.1 \%)$. Therefore, below the average of study participants had good knowledge and attitude towards IDD and prevention approach (Table 2). The association of poor knowledge towards
IDD statically more significant among illiterate women than those women who had secondary education $[\mathrm{AOR}=4.61 ; 95 \% \mathrm{CI}=(3.03$, 7.02)] which was very strong association of IDD decreasing while study subjects education level increasing; Women who lived with less $(<1000$ ETB) household income had more than 3 times poor knowledge about IDD [AOR=3.07; 95\% CI $(1.28,7.39)]$ compared to those who lived with annual income of more than 1000 ETB. Among women those did not hear about information on iodised salt utilization had unfortunate knowledge about IDD more than 2 times compared to women who heard these information [AOR= 2.43; 95\%CI(1.74,3.40)] (Table 3).

Table 3: Bivariate and multivariable logistic regression models predicting the likelihood of good knowledge about IDD among women in Central highland, Ethiopia.

\begin{tabular}{|c|c|c|c|}
\hline categories & \multicolumn{3}{|c|}{ Knowledge towards IDD } \\
\hline Maternal Age & Good $n(\%)$ & Poor n (\%) & AOR (95\%CI) \\
\hline Age $<20$ & & $25(2.47)$ & $1.38(0.76,2.52)$ \\
\hline Age 2035 & $63(6.23)$ & $179(17.69)$ & $1.04(0.68,1.59)$ \\
\hline Age>35 & $597(59.00)$ & $33(3.26)$ & 1 \\
\hline Secondary education & $115(11.36)$ & $48(4.74)$ & 1 \\
\hline Primary education & Education Level & $1.72(1.15,2.57)^{*}$ \\
\hline Read and write & $247(24.40)$ & $60(5.93)$ & $3.56(2.26,5.60)^{*}$ \\
\hline Illiterate & $34(3.36)$ & $105(10.37)$ & $4.61(3.03,7.023)^{*}$ \\
\hline
\end{tabular}

Cite this article: Abebe F, Muluemebet A, Tefera B. Knowledge and Attitude about Prevention of Iodine Deficiency Disorders (IDD) among Women and Quantification of Iodide found in Table Salt in Central Highland of Ethiopia. Biomed J Sci \& Tech Res 12(2)-2018. BJSTR. MS.ID.002229. DOI: $10.26717 /$ BJSTR.2018.12.002229. 


\begin{tabular}{|c|c|c|c|}
\hline \multicolumn{3}{|c|}{ Annual income in Ethiopian currency } & \multirow[b]{2}{*}{1} \\
\hline$>6,000$ & $44(4.34)$ & $6(0.59)$ & \\
\hline $3001-6,000$ & $122(12.05)$ & $28(2,77)$ & $1.68(0.65,4.33)$ \\
\hline $1000-3,000$ & $294(29.05)$ & $71(7.01)$ & $1.77(0.72,4.31)$ \\
\hline$<1000$ & $315(31.13)$ & $132(13.04)$ & $3.07(1.28,7.39)^{*}$ \\
\hline \multicolumn{4}{|c|}{ Usual time for adding iodised salt during food cooking } \\
\hline End of cooking & 173(17.09) & $53(5.24)$ & 1 \\
\hline Mid cooking time & $162(16.01)$ & $48(4.74)$ & $0.98(0.62 .1 .51)$ \\
\hline Early cooking time & $440(43.48)$ & $136(13.44)$ & $1.01(0.70,1.45)$ \\
\hline \multicolumn{4}{|c|}{ Access of communication on iodised salt utilization } \\
\hline Yes & $653(64.52)$ & 163(16.10) & 1 \\
\hline NO & $122(12.05)$ & $74(7.31)$ & $2.43(1.74,3.40)^{*}$ \\
\hline \multicolumn{4}{|c|}{ Handling table salt in dray container with cover } \\
\hline NO & $244(24.11)$ & $74(7.31)$ & $1.01(0.74,1.38)$ \\
\hline Yes & $531(54.45)$ & 163(16.10) & 1 \\
\hline \multicolumn{4}{|c|}{ Specific storage place for table salt } \\
\hline Yes & $671(66.30)$ & $198(19.57)$ & 1 \\
\hline NO & 104(10.27) & $39(3.85)$ & $0.71(0.52,0.95)^{*}$ \\
\hline \multicolumn{4}{|c|}{ Consume cabbage, potato as staple food } \\
\hline Yes & $258(25.49))$ & $107(10.57)$ & 1 \\
\hline NO & $488(48,22)$ & $130(12.84)$ & $1.27(0.85,2.00)$ \\
\hline
\end{tabular}

Note:" AOR- Adjusted Odds Ratio, CI- Confidence interval, Birr- Ethiopian currency, IDD- Iodine deficiency disorders.

\section{Table Salt Laboratory Results}

Standard titration test method was used to ensure the consumption of recommended levels of iodine in the population. The test result classified in to three categories; based on their iodine content $(\mathrm{ppm}=\mathrm{mg}$ iodine per $\mathrm{kg}$ of salt): under standard values $(<15 \mathrm{ppm})$; allowable standard values (15-40ppm) and over standard values (>40ppm) [9]. Tests showed that $73(60.83 \%)$ of the households salt had allowable in standard limit and 46 (38.33\%) samples had over standard value iodide in salt and $1(0.83 \%)$ of the HH had blow standard limit. Therefore, 119 (99.17\%) households were with adequately iodised salt and the requirement of iodine per person per day also satisfactory. The mean and standard deviation of the salt iodine content were $45.29(\mathrm{SD}+14.47)$. The maximum and the minimum value of iodine in milligram $(\mathrm{mg})$ per kilogram $(\mathrm{kg})$ of salt were 84 and 15 respectively. The most frequent value was 58ppm, 25 percentile was 36.04 and 75 percentile was 56.18 . The distribution of iodine in $\mathrm{mg} / \mathrm{kg}$ of salt (ppm) among the households was normal. There was significant relationship between iodine values in table salt samples taken from the HHs compeered to World
Health Organization standard iodine values 40 ppm ( $\mathrm{P}=0.001)$.

Samples of salt from the HHs were statistically significant compared with mean iodine values in $\mathrm{mg} / \mathrm{kg}$ in table salt $(\mathrm{P}=0.001)$. This study included table salt samples from shops and markets were collected and analysed to ensure under quantity of iodised salt and the leakage of non-iodized salt into the general population which could limit the elimination of IDD [9]. Table salt samples taken from headquarter markets and shops test results showed that $9(37.53 \%)$ had standard limit and $15(62.5 \%)$ had above standard limit and no sample fund blow the standard limit of iodine in ppm which means less unconventional marketing sources for non iodine salts. The mean and SD of iodine for table salt test sampled collected from markets were 47.31(+16.4) and the most frequent value was $58.3 \mathrm{ppm}$ of iodine in salt, The distribution of iodide in $\mathrm{mg} / \mathrm{kg}$ of salt (ppm) among headquarter markets was normal. Each headquarters market and shop titration test results indicate that the maximum iodide table salt was $83.74 \mathrm{ppm}$ found in Sagure town market and the minimum value was $16.96 \mathrm{ppm}$ found in L.Michael market (Table 4). 
Table 4: Titration test method results for table salt samples collected from headquarter markets to determine iodine mg/ $\mathrm{kg}$ of salt (ppm).

\begin{tabular}{|c|c|c|c|c|}
\hline \multicolumn{5}{|c|}{ Samples collected January 01 to February11,2018 Date of laboratory analysis February 20, 2018} \\
\hline Markets and shops & Initial Volume In ml & Final Volume In ml & Difference Volume in ml & Iodine : in $\mathrm{mg} / \mathrm{kg}$ salt \\
\hline Market L. Burkitu & 6.2 & 11.6 & 5.4 & 57.24 \\
\hline Market L. Burkitu & 11.6 & 15.9 & 4.3 & 45.58 \\
\hline L. Burkitu shop & 15.6 & 18.8 & 3.2 & 33.92 \\
\hline Market L. Dima & 18.8 & 23.6 & 4.8 & 50.88 \\
\hline Market L. Dima & 0 & 4.6 & 4.6 & 48.76 \\
\hline L.Michael Shop & 4.6 & 9.1 & 4.5 & 47.7 \\
\hline Market L. Michael & 9.1 & 12.6 & 3.5 & 37.1 \\
\hline Market L. Michael & 12.6 & 14.2 & 1.6 & 16.96 \\
\hline Shop Bekoji town & 14.2 & 19.1 & 4.9 & 51.94 \\
\hline Shop Bekoji town & 19.1 & 24.6 & 5.5 & 58.3 \\
\hline Shop Bekoji town & 6.1 & 9 & 2.9 & 30.74 \\
\hline Market Bekoji & 9 & 14.5 & 5.5 & 58.3 \\
\hline Market Bekoji & 14.5 & 17 & 2.5 & 26.5 \\
\hline Market Bekoji & 17 & 19.5 & 2.5 & 26.5 \\
\hline Market Bekoji & 19.5 & 25 & 5.5 & 58.3 \\
\hline Market Ashebeka & 0 & 3.2 & 3.2 & 33.92 \\
\hline Market Ashebeka & 3.2 & 6.7 & 3.5 & 37.1 \\
\hline Market Sagure & 6.7 & 14.3 & 7.6 & 80.56 \\
\hline Market Sagure & 14.3 & 22.2 & 7.9 & 83.74 \\
\hline Market Sagure & 18.2 & 24.6 & 6.4 & 67.84 \\
\hline Market Asella & 0 & 5 & 5 & 53 \\
\hline
\end{tabular}

\section{Discussion}

Adequacy of information about the use and utilization of iodised salt to individuals and households is the major approach to control IDD [10]. Although, strengthening evaluation and monitoring system for knowledge and attitude on iodised salt utilization and measuring table salt iodide content are a decisive step to eradicate iodine deficiency [9]. As a result, the percentage for access to iodised salt utilization communication was $63.0 \%$ and below the average $(44.7 \%)$ of study participants had awareness to IDD. Our finding approached below to the report of a study in Axum town that has showed that $80 \%$ of study participants knew iodized salt can prevent IDD [12]. This variation from our finding might perhaps be due to study setting was urban areas after and the population have better education which enable them exchange information easily but this study was mainly included the rural part of the country. Study participants who had good knowledge of iodized salt use were $64.92 \%$ and this finding was lesser than finding in Addis Ababa which was 78\% [13]. The difference might be due to high percentage of study participants had good education level which enables them to increase opportunities deal about IDD prevention and iodised salt utilization.

Communication barriers also very less among people those had good knowledge compared to the current study. In our finding subjects who had appropriate time for adding iodised salt during food cooking was $22.3 \%$ which had a very low when compared study finding in Wolaita that is $36.1 \%$ [14]. This difference could be due to differences in location and range of covered area by the study. Study participants who had conclusive intake of iodine to prevent IDD was $47.8 \%$ and comparatively lower than study finding in Axum town that has 56\% [12]. Study participants from their households represented sufficient table salt samples and these would enable us to inference for the wide community. In addition to this, using standard procedure for quantifying iodide found in table salt ensure the level of iodine intake even if utilization factors limit the adequacy of iodine for the prevention of IDD. In our study, high proportion of households (99.1\%) had standard quantity of iodine $(>15)$ and unacceptable levels of iodised salt was very less $(0.83 \%)$. Our study finding clearly stated that samples taken from headquarters markets had $100 \%$ standard limit of iodine quantity in table salt and categorized into standard iodized limit was $37.5 \%$ and $40.83 \%$ was over standard iodised limit.

Therefore, the proportion of salt samples collected from major headquarters markets found potentially iodized in accordance with the average requirement $(150 \mu \mathrm{g}$ per person/day) of iodine. For that reason, successful introduction and accessed for iodised salt in the study area was good opportunity in the progress to reduce 
the risk of iodine deficiency. History of iodised salt in Ethiopia expressed in different literatures and international documents. In 2008, United Nations Children's Fund (UNICEF) declared through revision on the progress in households consuming adequately iodized salt in Ethiopia since 1995had not greater than 20\% [15]. A national surveys data analysis for iodised salt coverage reported that $8 \%$ of households had table salt added with iodine and more than one-half of the household population remains at risk of iodine deficiency [16]. Consistently, Ethiopian demographic health survey (EDHS) justified that not excel than $16 \%$ of $\mathrm{HH}$ used adequate iodised salt at national level and at different region of Ethiopia have under average of HH had adequate iodine through iodised salt [17].

The testimony of EDHS in 2000 reported that $28 \%$ of the $\mathrm{HH}$ consumed adequately iodized salt which was very similar finding with the past more than 2 decades. However, the urging of health problem from iodine deficiency exposure enhances the emerging of iodisation. The rapid establishment of two main iodisation plants and hundreds of small-scale units have been functioning and these made great progress since 2002 in Ethiopia [18-20]. So, small and large scale iodisation products delivered to the market and to the $\mathrm{HH}$ need standard quantification and this optimistic to prove the past ten years accesses compared to the current situation [16]. A study conducted in Asella town with rapid kit test showed that the percentage of HHs with consumed adequately iodized salt was $62.9 \%$ and this shows better change to ensure iodised salt intervention for the prevention of IDD than before [21].

Additionally, study finding conducted in Northwest of Ethiopia showed that about $33.2 \%$ of households had adequately iodized salt which is far different with our finding [22]. The national survey which has carried out to measure the progress of adequacy of iodized in Ethiopia conducted using titration method in 2015 indicated that $26 \%$ of the household have standard iodised salt (ppm) [23]. The current study finding reported that about $99.1 \%$ of the HH had table salt with adequate amount iodine (ppm) which was higher than study conducted in Asella town and in Northwest Ethiopia because both studs used rapid test which were deficient to predict the amount of iodine in salt (ppm). But this study made high reliable titration test and addressed wide-range of study area and high population (HHs and headquarter markets) were included in the study. In more, investment on iodisation plants relatively increasing within short period than the past years and this increasing comparative access and quantity of iodine in the country [19].

Andersson $\mathrm{M}$ et al. reported that nearly 150 countries have markedly improved the global iodine nutritional status their population and this is reaction decreased in the number of iodinedeficient countries worldwide from 54 in 2003 to 32 in 2011 [24]. Also, Ethiopia will successfully decrease risk of iodine-deficient problems in the population as our study shows that overall quantity of iodide found in table salt was greater than $90 \%$ satisfactory as confirmed by international standard tests. Mentoring and evaluation on production of standard iodised salt that will be distributed into the community shall be continuously assessed. The other core concerns are increasing knowledge of the household in utilization and changing their attitude through upgrading behavioral change communication need concentrated attention in developing countries to elimination of IDD.

This study issued rural peoples' knowledge and attitude toward worldwide nutritional problems from risk of inadequate intake of iodine. Thereafter, our finding shows that most of them had less knowledge and attitude IDD prevention and iodised salt utilization. These shows the risk area like central highland area need high investment communication to increase peoples' awareness on iodised salt utilization to prevent IDD. This study highlighted iodised salt access was higher and most of HHs consumed adequate quantity of iodide ppm throughout the community. The majority of iodized salt samples from the $\mathrm{HH}$ and market contained high amount of iodine more than the standard limit. Currently, we have been recommended to collect urine specimens to study Mid Urine Iodine Concentration persuasively on this study population's child. This test of iodine concentrations in urine will provide adequate information on the iodine nutrition a profile of this study community.

\section{Acknowledgment}

Authors would like to thanks Arsi University for financial support. Our special gratitude also goes to local administrative health office of study area, study participants, health post facility workers for their considerable cooperation at the time of data collection. Furthermore, we would like to express our deep appreciation towards Arsi Zonal Health Department and Ethiopian Public Health Institute and EPHI food and nutrition laboratory workers for their unlimited technical support.

\section{Ethical Approval}

This research was approved by Ethical Review Committee of Jimma University. Letter of permission was obtained from Arsi Zone administrative and health department offices. At the end, we obtained permission from 8 district administrative offices 16 Kebeles (Smallest Administrative Units) which were site for data collection administrations offices. In addition, all of the study participants $\mathrm{HH}$ were informed about the purpose of the study. The respondents were notified that they have the right to refuse or terminate at any point of our request of table salt. The information provided by each respondent was kept confidential.

\section{Funding}

Research was funded by Jimma University

\section{References}

1. Hetzel BS (1983) Iodine deficiency disorders (IDD) and their eradication. Lancet 2: 1126-1129.

2. Zewdie Wolde Gebriel (1992) Micronutrient deficiencies in Ethiopia and their inter-relationships, Landbouw universiteit Wageningen.

3. Benmiloud M, Bachtarzi H, Chaouki MB (2018) Public health and nutritional aspects of endemic goitre and cretinism in Africa. In: Delange F, Ahluwalia R (Eds.), Cassava toxicity and thyroid. Research and Public Health Issues, IDRC, Ottawa, p. 50. 
4. (1995) International Council for Control of Iodine Deficiency Disorders: Salt iodization for the elimination of iodine deficiency: The micronutrient initiative, Netherlands, Europe.

5. Zimmermann MB (2012) The effects of iodine deficiency in pregnancy and infancy. Pediatric and Perinatal Epidemiology: Laboratory for Human Nutrition, Institute of Food, Nutrition and Health, Swiss Federal Institute of Technology, pp. 108-117.

6. (1994) World Health Organization. Iodine and health: A statement by WHO.

7. Nathan R (1995) Food fortification legislation and regulation manual, ( $2^{\text {nd }} E d n$.) Atlanta, GA, Program against Micronutrient Malnutrition.

8. (2001) Food and Nutrition Board, Institute of Medicine. Dietary Reference Intakes. Washington, DC: National Academy Press, pp. 258289.

9. (2001) World Health Organization Assessment of Iodine Deficiency Disorders and Monitoring their Elimination A guide for program managers, $\left(2^{\text {nd }}\right.$ Edn. $)$.

10. Aburto NJ, Abudou M, Candeias V, Wu T, Organization WH (2014) Effect and safety of salt iodization to prevent iodine deficiency disorders: a systematic review with meta analyses. Geneva: World Health Organisation.

11. Aklilu Mekasha, Lisanework Nigatu, Kindie Tesfaye, Alan J Duncanc (2013) Modeling the response of tropical highland herbaceous grassland species to climate change: The case of the Arsi Mountains of Ethiopia. Biological Conservation 168: 169-175.

12. Hadgu Gerensea, Abadit Yohannse, Berhe Baymont, Hagos Atsbha, Kidan Nguse, et al. (2015) Knowledge, attitude and practice (KAP) towards iodized salt utilization in Hawelti Kebelle, Axum, Tigray, Ethiopia. Edorium J Nutr Diet 2: 1-8.

13. Meseret Mamo Bazezew, Walelegn Worku Yallew, Aysheshim kassahun Belew (2018) Knowledge and practice of iodized salt utilization among reproductive women in Addis Ababa City. BMC Res Notes 11: 734.

14. Wondimagegn Paulos, Yusuf Haji, Junayde Abdurahmen, Yohannes Mehretie Adinew (2018) Factors Affecting the Presence of Adequately

ISSN: 2574-1241

DOI: 10.26717/BJSTR.2018.12.002229

Abebe Ferede. Biomed J Sci \& Tech Res

(C) (i) This work is licensed under Creative

BY Commons Attribution 4.0 License

Submission Link: https://biomedres.us/submit-manuscript.php
Iodized Salt at Home in Wolaita, Southern Ethiopia: Community Based Study. International Journal of Food Science.

15. (1990) Sustainable elimination of iodine deficiency progress since the 1990. World Summit for Children.

16. Jacky M Knowles, Greg S Garrett, Jonathan Gorstein, Kupka R, Situma R, et al. (2017) Household Coverage with Adequately Iodized Salt Varies Greatly between Countries and by Residence Type and Socioeconomic Status within Countries: Results from 10 National Coverage Surveys. The Journal of Nutrition 147(5): 1004S-1014S.

17. (2012) Central Statistical Agency Ethiopia. Ethiopia Demographic and Health Survey 2011.

18. Chandrakant S Pandav, Narendra K Arora, Anand Krishnan, Rajan Sankar (2000) Field validation of salt iodine spot testing kit using multiple observers to assess the availability of iodized salt. Amsterdam, Elsevier pp. 1039-1043.

19. Maria Andersson, Bahi Takkouche, Ines Eqli, Ines Egli, Henrietta E. Allen, Bruno de Benoist (2005) Current global Iodine Nutrition status and progress over the last decade toward the elimination of iodine deficiency Bulletin World Health Organization 83(7): 518-525.

20. (2005) UNICEF. Control and Prevention of Iodine Deficiency Disorders (IDD) in Ethiopia. UNICEF Addis Ababa.

21. Hawas SB, Lemma S, Mengesha ST, Demissie HF, Segni MT (2016) Proper Utilization of Adequatly Iodized Salt at House Hold Level and Associated Factores in Asella Town Arsi Zone Ethiopia: A Community based Cross Sectional Study. J Food Process Technol 7: 4.

22. Zegeye Abebe, Amare Tariku and Ejigu Gebeye (2017) Availability of adequately iodized in Northwest Ethiopia: a cross-sectional study. Archives of Public Health 75: 33.

23. Andinet Hailu (2017) Remarkable progress against iodine deficiency in Ethiopia. Ethiopian National Micronutrient Survey Report: Ethiopian Public Health Institute, Ministry of Health 2016 IDD Newsletter.

24. Andersson M, Karumbunathan V, Zimmermann MB (2012) Global iodine status in 2011 and trends over the past decade. J Nutr 142(4): 744-750.

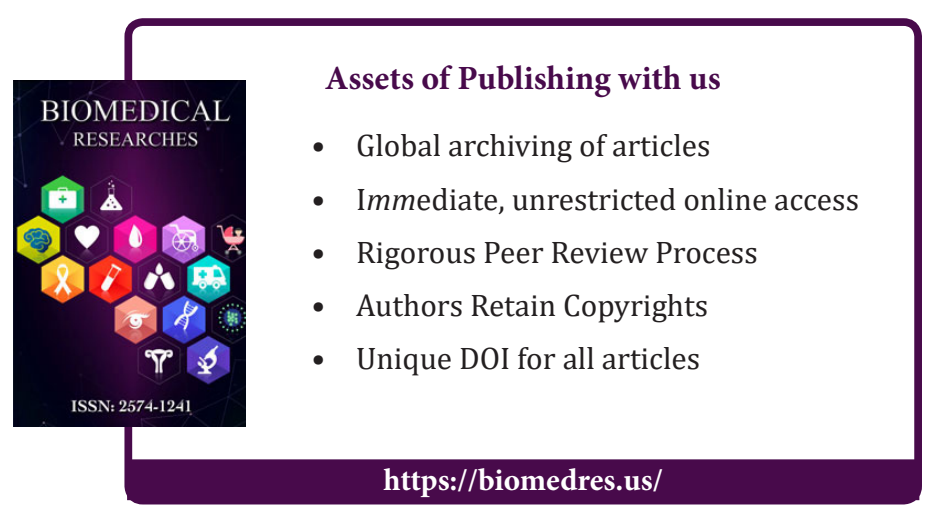

